\title{
Low co-expression of epidermal growth factor receptor and its chaperone heat shock protein 90 is associated with worse prognosis in primary glioblastoma, IDH-wild-type
}

\author{
ELSA SARTORI $^{1}$, RUPERT LANGER ${ }^{1}$, ERIK VASSELLA ${ }^{1}$, EKKEHARD HEWER ${ }^{1}$, \\ PHILIPPE SCHUCHT $^{2}$, INTI ZLOBEC ${ }^{1}$ and SABINA BEREZOWSKA ${ }^{1}$ \\ ${ }^{1}$ Institute of Pathology, University of Bern, 3008 Bern; ${ }^{2}$ Department of Neurosurgery, Inselspital, \\ Universitätsspital Bern, 3010 Bern, Switzerland
}

Received January 13, 2017; Accepted July 5, 2017

DOI: $10.3892 /$ or.2017.5863

\begin{abstract}
Epidermal growth factor receptor (EGFR) is a major oncogenic driver in glioblastoma (GBM) without mutations in the isocitrate dehydrogenase gene (IDH-wildtype). Heat shock protein 90 (HSP90) is a regulator of the stability of oncogenic proteins including EGFR, thereby acting as a molecular chaperone. We investigated the expression of EGFR and its chaperone HSP90 in GBM, IDH-wildtype. Tissue availability permitted analysis of 237/449 consecutive GBM cases, among them 214 IDH-wildtype (90.3\%). The expression of EGFR and HSP90 was analysed by immunohistochemistry on a tissue microarray containing various tumour regions. The expression intensity (EI), and an expression score (ES) combining the percentage of stained cells with EI were determined for both markers. Overall, there was a positive correlation between EGFR and HSP90 expression (EI; $r=0.275, \mathrm{P}<0.001$; $\mathrm{ES}, \mathrm{r}=0.333, \mathrm{P}<0.001)$. The expression of EGFR and HSP90 was significantly higher in the tumour centre, compared to the infiltration front $(\mathrm{EI}, \mathrm{P}=0.002 ; \mathrm{ES}, \mathrm{P}<0.001)$. Survival data were available in 96 IDH-wildtype cases, and high expression of EGFR (ES only) was in trend associated with better outcome, but failed to meet statyistical significance $(\mathrm{P}=0.061)$. A combination of EGFR and HSP90, however, discriminated between different prognostic groups, with EGFR ${ }^{\text {low }} / \mathrm{HSP}^{\text {low }}$ tumours showing the worst prognosis in univariate analysis $(\mathrm{P}=0.001)$, and in multivariate analysis including the other relevant prognostic factors age, MGMT status and postoperative treatment $[n=76$; hazard ratio $(H R)=0.571 ; 95 \%$ confidence interval (CI) 0.328-0.996; $\mathrm{P}=0.048]$. EGFR expression stratified most pronounced among HSP90 ${ }^{\text {low }}$ tumours, where the EGFR $^{\text {high }}$ phenotype was associated with longer survival. Our
\end{abstract}

Correspondence to: Dr Sabina Berezowska, Institute of Pathology, University of Bern, Murtenstrasse 31, 3008 Bern, Switzerland

E-mail: sabina.berezowska@pathology.unibe.ch

Key words: heat shock proteins, HSP90, EGFR, GBM, glioblastoma, IDH-wild-type results reveal a variable reliance on the signalling pathway by EGFR in GBM, IDH-wildtype. Low co-expression was associated with worse prognosis.

\section{Introduction}

Glioblastoma (GBM) is the most common primary malignant brain tumour, and one of the most aggressive neoplasms, considered incurable, and classified as grade IV by the World Health Organization (WHO) (1). Despite current standard multimodal therapy concepts (excision, radiation and chemotherapy) 1-year survival reaches $37.2 \%$ and 5-year survival only $5.1 \%$ in unselected GBM patients across all age groups (2). Incidence of GBM increases with age, paralleled by increasingly worse prognosis (2).

In the WHO classification 2016, which for the first time also incorporates molecular parameters for tumour typing, GBM harbouring mutations in the isocitrate dehydrogenase gene (IDH) and those without (GBM, IDH-wildtype) are perceived as two very different disease entities, differing in molecular alterations, precursor cells and prognosis $(1,3,4)$. IDH-wildtype GBM is synonymous to primary GBM, arising de novo predominantly in the older age group, and having a worse prognosis. One of the hallmark alterations of this predominant GBM-subtype (comprising 90\%) are high-level gene amplifications of certain proto-oncogenes most commonly the epidermal growth factor receptor (EGFR) gene. This results in EGFR overexpression, and as a late event, constituitively activating mutations, mainly the variant III (vIII) deletion (3). IDH-mutant (secondary) GBMs arise from lower grade gliomas, affect younger patients, and have a comparably longer survival $(1,4,5)$. Most of the IDH point mutations in GBM affect the amino acid arginine at position 132 (R132H-IDH1), and can be visualized using immunohistochemical staining (IHC) (6). In case of negative IHC, sequencing should be applied in patients younger than 54 years of age in order to safely exclude IDH-mutant GBM (1).

Treatment options for GBM are limited. Complete resection is virtually impossible due to its highly infiltrative growth. Resistance to chemotherapy and radiation result in the inevitable treatment failure. Targeted therapies may 
permit individualized treatment of different molecular GBM-subtypes. Exploiting molecular alterations for targeted therapeutic approaches has proved successful in other malignant neoplasms, e.g. anti-EGFR tyrosine kinase inhibitors (TKI) in EGFR-dependent non-small cell lung cancer (7).

EGFR displays its oncogenic potential also in GBM $(8,9)$. By dysregulation, amplification or mutation, EGFR acts as an activator of signalling pathways, stimulating cell proliferation, anti-apoptosis, angiogenesis, invasion and metastasis $(8,10)$. Despite this rationale, clinical studies using TKI against EGFR have shown insufficient efficacy to date (11). Multitarget approaches may be needed.

Heat shock proteins (HSPs) are highly conserved molecular chaperones, i.e. molecules enabling proper folding and stabilization of their client proteins (12). HSPs belong to the cellular stress response machinery e.g. to heat shock, hence the name, and are categorized by approximate molecular weights. By stabilizing and maturating oncogenic proteins, HSPs contribute to tumour invasiveness, angiogenesis and metastasis, making them putative therapeutic targets $(12,13)$. EGFR and many molecules of the downstream Akt/PI3K and MAPK pathways are important client proteins of HSP90. In the last years, targeting HSP90 has emerged as possible anticancer therapy, alone or in combination with other drugs or radiotherapy $(12,14,15)$.

Therefore, in the present study, we aimed to assess the co-expression patterns and any prognostic significance of EGFR and its chaperone HSP90 in the subgroup of GBM, IDH-wildtype.

\section{Materials and methods}

Patient cohort. The initial study cohort comprised all consecutive patients diagnosed with GBM at the Institute of Pathology, University of Bern, Switzerland, between 2000 and 2012 (16). All biopsies and resections were performed in the Department of Neurosurgery, Inselspital, University Hospital Bern, Switzerland. The clinicopathological data were collected from pathology reports and a clinical database (Swiss Glioma Network). This retrospective study was conducted according to the REMARK guidelines $(17,18)$, and was approved by the Cantonal Ethics Commission of the Canton of Bern (KEK 200/14), which waived the requirement for written informed consent.

In total, we identified 449 patients with GBM in our database. In 237 cases, sufficient formalin fixed and paraffin-embedded (FFPE) tissue was available for construction of a tissue microarray (TMA). Material availability was assessed on hematoxylin and eosin stained slides and the corresponding paraffin blocks. Thus, material originating from stereotactic biopsies was insufficient for inclusion. To avoid confounding factors of immunohistochemical analysis, tissue that had been frozen for intraoperative assessment using cryosections before fixation in formalin was excluded.

TMA. A TMA was constructed as previously described: slides were scanned, digitally annotated and punched using the TMA Grand Master (3DHISTECH, Budapest, Hungary) (19). Whenever possible, 4 cores each (diameter, $0.6 \mathrm{~mm}$ ) derived from the: i) tumour centre; ii) infiltration edge; and iii) distant non-neoplastic tissue from each tumour were included.
Immunohistochemistry. The TMA blocks were sectioned at $3 \mu \mathrm{m}$, and stained using an automated immunostainer Leica Bond III system (Leica Biosystems, Newcastle, UK). Staining conditions including primary antibodies and antigen retrieval were as following: mouse monoclonal R132H-mutant IDH antibody, clone H09 (ref. DIA-H09; Dianova, Hamburg, Germany), 1:50, Tris-EDTA buffer $\mathrm{pH} 9$ at $95^{\circ} \mathrm{C}, 30 \mathrm{~min}$; mouse monoclonal HSP90 antibody, clone S88 (ref. ab1429; Abcam, Cambridge, UK), 1:25, citrate buffer $\mathrm{pH} 6$ at $100^{\circ} \mathrm{C}$, $30 \mathrm{~min}$ and mouse monoclonal wildtype EGFR antibody, clone DAK-H1-WT (ref. M7298; Dako, Gloustrup, Denmark), 1:50, Tris-EDTA buffer $\mathrm{pH} 9$ at $95^{\circ} \mathrm{C}, 30 \mathrm{~min}$. All secondary antibodies, the chromogen (3,3'-diaminobenzidine) and the hematoxylin counter-stain were included in the visualization system, Bond Polymer Refine Detection (Leica Biosystems).

For scoring of immunohistochemical markers, we assessed the staining intensity ranging from 1 (negative or traces); 2 (weak); 3 (medium) to 4 (strong) for EGFR; and ranging from 1 (negative or traces), 2 (weak) to 3 (strong) for HSP90, according to published scoring systems for both EGFR (20) and HSP90 (21) on glioma cells (Fig. 1). The percentage of stained cells was determined as follows: $1, \leq 10 \% ; 2,11-50 \%$; and $3, \geq 50 \%$. The expression was assessed for every TMA core separately and the mean across all cores was calculated to determine the final expression intensity (EI) and an expression score (ES). ES was defined as the product of EI and the percentages of positive cells.

IDH sequencing and assessment of MGMT promoter methylation. DNA was extracted from tissue sections containing at least 70\% tumour cells using the Qiagen EZ1 tissue kit (Qiagen, Hombrechtikon, Switzerland) according to the manufacturer's instructions. The mutational status of the IDH1 and IDH2 genes was assessed by pyrosequencing as previously described (22,23). MGMT promoter methylation was determined using a primer extension-based quantitative assay as already reported (24).

Statistical analysis. Descriptive and comparative statistical analyses were performed using IBM SPSS Statistics 23 (IBM Corp., Armonk, NY, USA). We applied Spearman's Rho test for correlation analysis, and evaluated associations between staining patterns and categorical parameters using simple cross tabs ( $\chi^{2}$-test or Fisher's exact test). For binded samples, we used the Wilcoxon test. Survival analysis was performed by log-rank test (univariate) and Cox regression analysis (multivariate). The significance level was set at $\mathrm{P}<0.05$.

\section{Results}

Patient cohort. In total, 449 patients with GBM were initially identified, with a male to female ratio of 271 (60.4\%) and 178 (39.6\%), and a median age at surgery of 61 years (range 21-88).

The TMA sub-collective comprised of 237 patients, $136(57.4 \%)$ men and $101(42.6 \%)$ women. Age at the time of surgery ranged from 24-85 years (median 59 years) (Table I), comparable to the initial cohort (data not shown). Using immunohistochemistry, 23/237 tumours (9.7\%) exhibited evidence of R132H-IDH1 mutations. Sequencing of IDH1 and IDH2 was performed on all 28 IHC-negative tumours from patients 

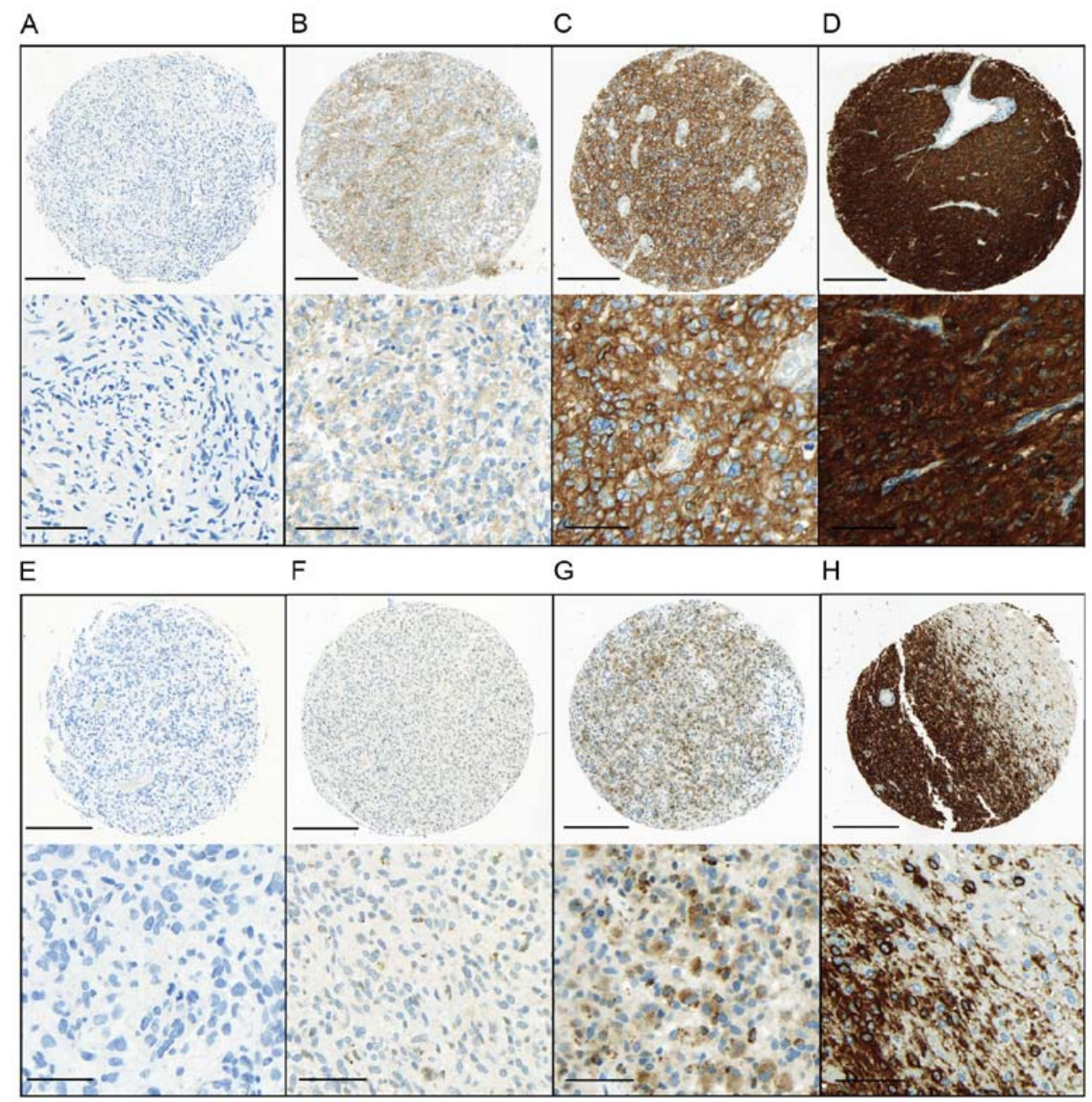

Figure 1. Immunohistochemical staining intensity for EGFR and HSP90. Upper panel, EGFR staining intensity was evaluated as (A) negative or traces, (B) weak, (C) moderate or (D) marked. Lower panel, HSP90 staining intensity was evaluated as (E) negative or traces, (F) weak or (G) marked. (H) EGFR staining pattern at the infiltration edge. All photomicrographs in the upper panels were captured at an objective magnification of x10 (scale bar, $200 \mu \mathrm{m}$ ). Detailed images of the staining are shown under each sample (objective magnification, $\mathrm{x} 40$; scale bar, $50 \mu \mathrm{m}$ ). EGFR, epidermal growth factor receptor; HSP90, heat schock protein 90.

younger than 54 years of age at diagnosis, as recommended by the WHO 2016, but revealed no additional IDH-mutant tumours (1). Finally, 214/237 (90.3\%) cases were GBM, IDH-wildtype. The study cohorts are juxtaposed in Table I. MGMT methylation data was available in 106 cases of the TMA cohort.

Survival data were available for 102 patients of the TMA cohort, among them 96 GBM, IDH-wildtype. For these patients, additional information concerning post-operative treatment was extracted from the database: 88 patients $(85.4 \%)$ received postoperative combined radiation and chemotherapy (temozolomide), followed by bevacizumab in 44 patients. Seven patients $(6.8 \%)$ received radiation or chemotherapy only ( 3 only radiotherapy, 4 only chemotherapy), and 8 patients (7.8\%) did not receive any type of treatment.

Expression of EGFR and HSP90. The expression of EGFR and HSP90 was determined in the tumour centre in all 237 cases. Additionally, the infiltration zone was available for analysis in 161 cases and brain tissue distant from the tumour in 167 cases. In 33 cases, tumour tissue of recurrent disease was available, including the infiltration zone in 25 cases and brain tissue distant from the recurrent tumour in 18 cases. The expression levels evaluated as aforementioned ranged from 0-4 for EGFR EI and from 1-12 for EGFR ES (Fig. 1). For HSP90, EI was observed from 0-3, and ES ranged from 1-9. Overall, there was a statistically significant positive correlation between EGFR expression and HSP90 expression (EI, $r=0.275, \mathrm{P}<0.001$; $\mathrm{ES}, \mathrm{r}=0.333, \mathrm{P}<0.001$ ) (data not shown).

Differences of EGFR and HSP90 expression within tumour regions. The expression of EGFR (EI and ES) was significantly higher in the tumour centre, compared to the infiltration zone $(\mathrm{P}=0.002 ; \mathrm{P}<0.001)$ or distant brain tissue $(\mathrm{P}<0.001$ each $)$, and higher in the infiltration zone compared to distant brain tissue $(\mathrm{P}<0.001$ each; Fig. 2). Similar results were obtained for the recurrent tumours (data not shown). For HSP90 the patterns were comparable, with higher levels (EI and ES) in the tumour centre compared to the infiltration zone (in trend, but failing to meet statistical significance for EI, $\mathrm{P}=0.156$; ES, $\mathrm{P}=0.007)$ and distant brain tissue $(\mathrm{P}<0.001$ each), and higher levels in the infiltration zone compared to distant brain tissue ( $\mathrm{P}<0.001$ each; Fig. 2). Similarly, in recurrent tumours, higher HSP90 levels were detected in the tumour, however 
Table I. Clinicopathological parameters and the expression of EGFR/HSP90 in the total TMA-cohort and the GBM, IDH-wild-type sub-cohort (study cohort).

\begin{tabular}{|c|c|c|}
\hline & $\begin{array}{l}\text { TMA-cohort, } \\
\text { total, } \\
\mathrm{n}=237 \\
\mathrm{n}(\%)\end{array}$ & $\begin{array}{l}\text { TMA-cohort, GBM, } \\
\text { IDH-wild-type, } \\
\text { n=214 } \\
\text { n }(\%)\end{array}$ \\
\hline \multicolumn{3}{|l|}{ Sex } \\
\hline Male & $136(57.4)$ & $124(57.9)$ \\
\hline Female & $101(42.6)$ & $90(42.1)$ \\
\hline $\begin{array}{l}\text { Age at operation, } \\
\text { (years), median } \\
\text { (range) }\end{array}$ & $59(24-85)$ & $60(27-85)$ \\
\hline $\begin{array}{l}\text { Overall survival, } \\
\text { (months), median } \\
(95 \% \mathrm{CI})\end{array}$ & $\begin{array}{c}19.0(14.1-23.9) \\
(n=102)\end{array}$ & $\begin{array}{c}17.0(13.4-20.6) \\
(n=96)\end{array}$ \\
\hline \multicolumn{3}{|l|}{$\begin{array}{l}\text { MGMT methylation } \\
\text { (data available } \\
\text { for } n=106 \text { ) }\end{array}$} \\
\hline Absent & $51(48.1)$ & $51(51)$ \\
\hline Present & $55(51.9)$ & $49(49)$ \\
\hline \multicolumn{3}{|l|}{$\begin{array}{l}\text { EGFR/HSP90 } \\
\text { expression }\end{array}$} \\
\hline EGFR $^{\text {low }} / \mathrm{HSP}^{\text {low }}$ & $77(32.5)$ & $66(30.8)$ \\
\hline $\mathrm{EGFR}^{\text {low }} / \mathrm{HSP} 90^{\text {high }}$ & $57(24.0)$ & $50(23.4)$ \\
\hline $\mathrm{EGFR}^{\text {high }} / \mathrm{HSP}$ 90 ${ }^{\text {low }}$ & $45(19.0)$ & $43(20.1)$ \\
\hline $\mathrm{EGFR}^{\text {high}} / \mathrm{HSP} 90^{\text {high }}$ & $58(24.5)$ & $55(25.7)$ \\
\hline
\end{tabular}

EGFR, epidermal growth factor receptor; HSP90, heat shock protein 90; TMA, tissue microarray; GBM, glioblastoma; IDH, isocitrate dehydrogenase; $\mathrm{CI}$, confidence interval.

with no differences between the centre and the infiltration zone (data not shown).

Differences between the primary tumour and recurrence. EGFR (ES) in the primary tumours were only in trend higher than in recurrent tumours $(\mathrm{P}=0.05$, data not shown), but this was not observed for $\mathrm{EI}(\mathrm{P}=0.523$, data not shown). For HSP90 there was no difference between the primary and recurrent tumours (EI, $\mathrm{P}=0.485$; $\mathrm{ES}, \mathrm{P}=0.338$ ).

Association of EGFR and HSP90 expression with clinicopathological parameters. IDH-wildtype GBM showed higher expression of EGFR than IDH-mutant GBM (EI, $\mathrm{P}=0.001$; ES $\mathrm{P}=0.005$ ), but lower levels of HSP90 (EI $\mathrm{P}=0.003$; ES P=0.494). No significant association was found for EGFR or HSP90 expression and age (cut-off, median), sex or MGMT status.

Survival analysis was performed on the TMA cohort, where survival data were available for 102 patients, among them 96 GBM, IDH-wildtype. Presence of IDH1 mutation $(\mathrm{P}<0.001)$ and younger age $(\mathrm{P}=0.026)$ were associated with a significantly better prognosis, without sex predilection $(\mathrm{P}=0.307)$. Lack of any MGMT-methylation was associated
Table II. Multivariate analysis in glioblastoma, IDH-wild-type $(n=76)$.

\begin{tabular}{|c|c|c|c|c|}
\hline \multirow[b]{2}{*}{ Parameter } & \multirow[b]{2}{*}{ HR } & \multicolumn{2}{|c|}{$95 \% \mathrm{CI}$} & \multirow[b]{2}{*}{ P-value } \\
\hline & & Min. & Max. & \\
\hline Age (median) & 0.839 & 0.497 & 1.418 & 0.513 \\
\hline MGMT & 0.438 & 0.248 & 0.773 & 0.004 \\
\hline $\begin{array}{l}\text { Postoperative } \\
\text { treatment }\end{array}$ & 1.674 & 1.267 & 2.212 & $<0.001$ \\
\hline $\begin{array}{l}\mathrm{EGFR}^{\text {low }} / \mathrm{HSP}^{\text {low }} \text { vs. } \\
\text { EGFR }^{\text {high }} / \mathrm{HSP}^{\text {high}} / \\
\text { mixed }\end{array}$ & 0.571 & 0.328 & 0.996 & 0.048 \\
\hline
\end{tabular}

IDH, isocitrate dehydrogenase; HR, hazard ratio; CI, confidence interval.

with worse outcome $(\mathrm{P}=0.003)$. Patients with combined postoperative radiation, temozolomide and bevacizumab treatment showed a better outcome, followed by radiation and chemotherapy, in contrast to radiation or chemotherapy only and no treatment $(\mathrm{P}<0.001)$.

For the determination of a potential prognostic impact of EGFR or HSP90 expression the median expression levels (EI and ES) in the tumour centre were used as cut-off for the discrimination into high and low expression (EGFR: EI, $\leq 3.25=$ low, $>3.25=$ high; ES, $\leq 9=$ low, $>9$ =high; HSP90: EI, $\leq 2=$ low, $>2=$ high; ES, $\leq 3.25=$ low, $>3.25=$ high). Low expression of EGFR (ES) was noted in 134/237 GBM (56.5\%), low expression of HSP90 (ES) in 122/237 (51.5\%). In the whole cohort, there was no association between EGFR or HSP90 and patient outcome in univariate analysis.

In IDH-wildtype GBM, low expression of EGFR (ES) was noted in 116/214 GBM (54.2\%), and low expression of HSP90 (ES) in 109/214 (50.9\%). High expression of EGFR (ES) was in trend associated with longer survival in univariate analysis but failed to meet statistical significance $(\mathrm{P}=0.061$, Fig. 3A; not significant for $\mathrm{EI}, \mathrm{P}=0.640)$. HSP90 expression alone was not prognostic ( $\mathrm{EI}, \mathrm{P}=0.614 ; \mathrm{ES}, \mathrm{P}=0.745$, Fig. 3B). However, a combination of EGFR and HSP90 expression strongly discriminated between different prognostic groups, with $\mathrm{EGFR}^{\text {low }} / \mathrm{HSP}^{\text {low }}$ tumours $(\mathrm{n}=66)$ showing the worst prognosis in contrast to EGFR ${ }^{\text {high }} / \mathrm{HSP}^{\text {high }}$ tumours $(\mathrm{n}=55)$ or mixed tumours ( $\mathrm{n}=93, \mathrm{P}=0.001$; Table I, Fig. $3 \mathrm{C}$ and D). In a multivariate model including the other relevant prognostic factors, age, MGMT status, and postoperative treatment, data on which were available as complete dataset for 76 patients, EGFR $^{\text {low }} / \mathrm{HSP}^{\text {low }}$ vs. EGFR ${ }^{\text {high }} / \mathrm{HSP}^{\text {lo }}{ }^{\text {high }} / \mathrm{mixed}$ was an independent prognostic factor $[n=76$; hazard ratio $(H R)=0.571$; $\mathrm{P}=0.048$, Table II]. This discrimination was not detectable for EI (univariate analysis; $\mathrm{P}=1.00$ ).

Regarding the particular subgroup of HSP90 ${ }^{\text {low }}$ GBM, IDH-wildtype, EGFR expression (ES) served as a prognostic factor (Fig. 3C), with a shorter survival of patients with low EGFR expression in univariate analysis $(\mathrm{P}=0.003)$, and reached almost statistical significance in a multivariate model encompassing age, MGMT status and postoperative therapy 

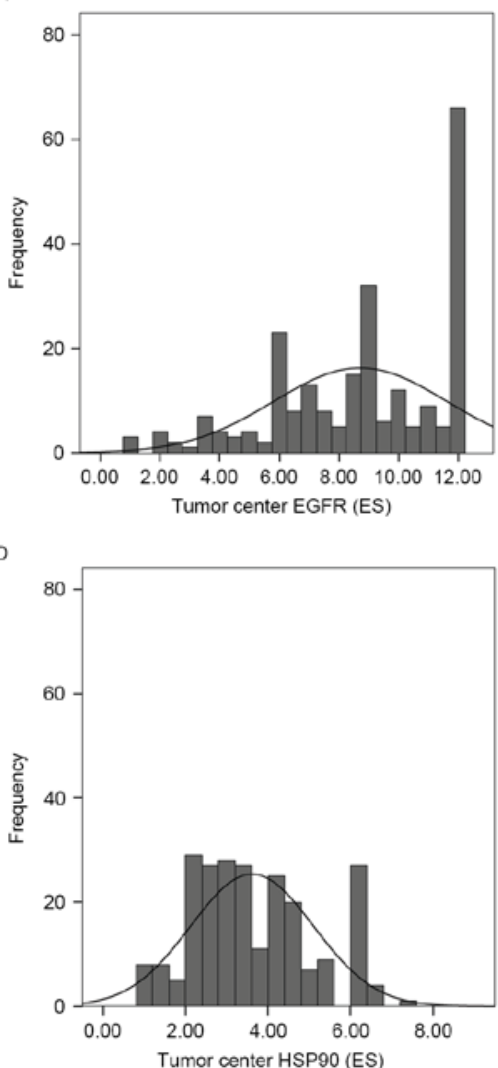
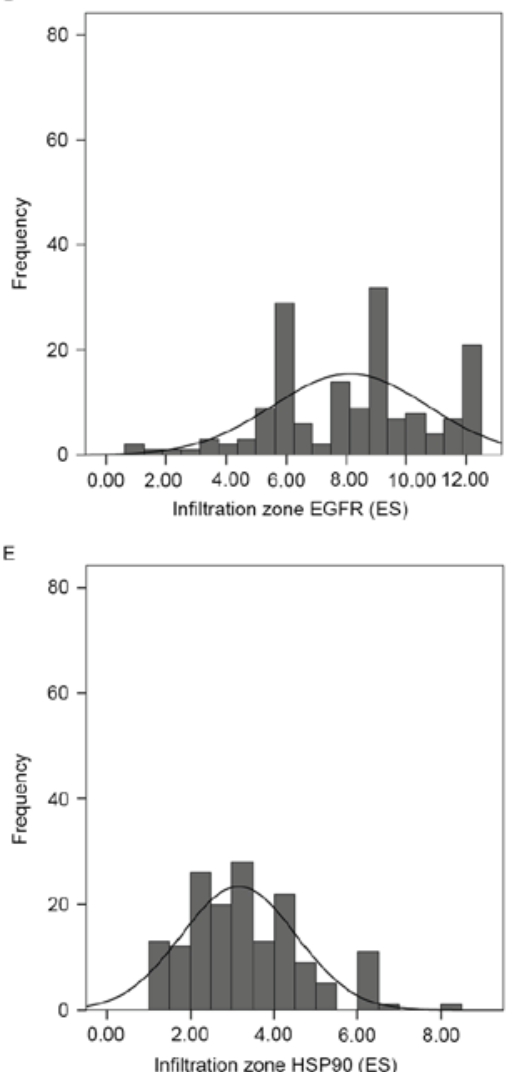
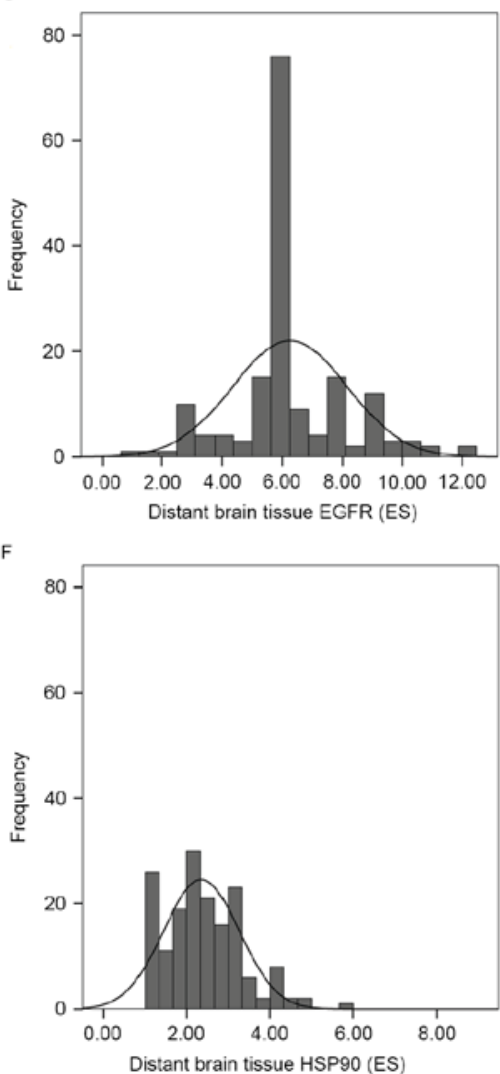

Figure 2. Distribution of the ES in the TMA-collective for (A-C) EGFR and (D-F) HSP90 in the (A and D) tumour centre, (B and E) infiltration zone and (C and F) distant brain tissue. ES, expression scores; TMA, tissue microarray; EGFR, epidermal growth factor receptor; HSP90, heat shock protein 90.

A
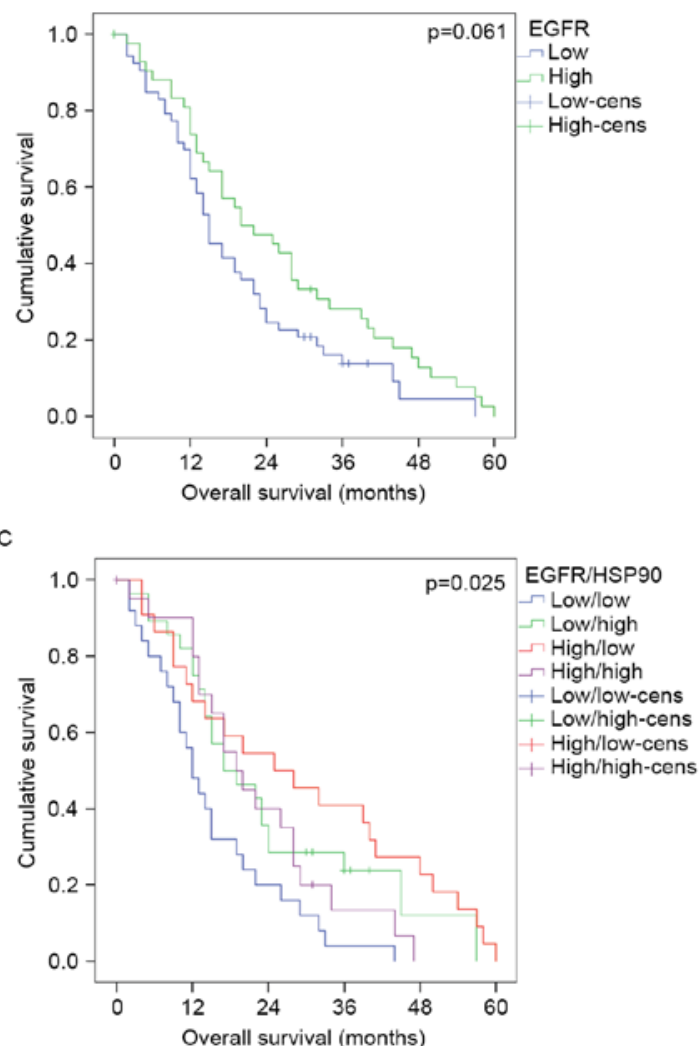
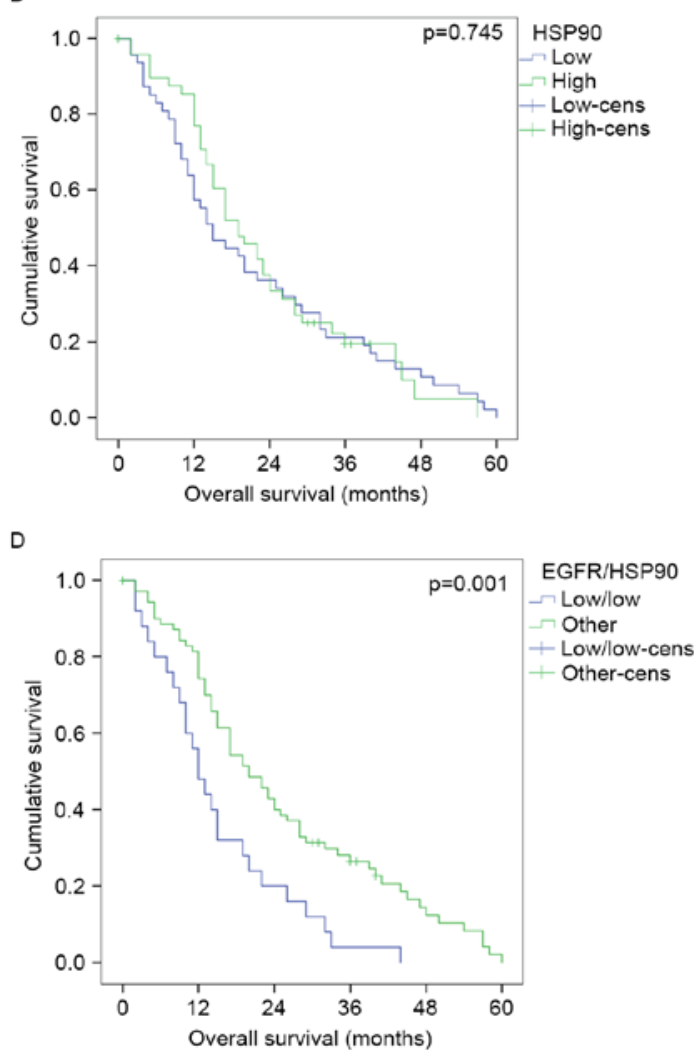

Figure 3. Kaplan-Meier curves for overall survival (months) in GBM, IDH-wild-type. (A) EGFR and (B) HSP90 expression levels show no significant association with outcome. (C and D) Combined EGFR and HSP90 expression levels show worse outcome in the EGFR ${ }^{\text {low }} / \mathrm{HSP}^{\text {low }}$ co-expressing group. GBM, glioblastoma; IDH, isocitrate dehydrogenase; EGFR, epidermal growth factor receptor; HSP90, heat shock protein 90. 
$[\mathrm{n}=47 ; \mathrm{HR}=0.465 ; 95 \%$ confidence interval (CI) 0.201-1.077; $\mathrm{P}=0.074]$. A prognostic value of EGFR was not apparent in the subgroup of $\mathrm{HSP} 90^{\text {high }}$ tumours (univariate analysis, $\mathrm{P}=0.617$ ).

\section{Discussion}

We report a retrospective, single-institution study on EGFR and HSP90 expression in GBM, IDH-wildtype. Despite a strong biological rationale, to the best of our knowledge this marker combination has not been investigated before in GBM. We revealed in the present study a positive correlation between the expression of both markers, and an independent prognostic value of EGFR and HSP90 co-expression, with worse prognosis in EGFR ${ }^{\text {low }} / \mathrm{HSP}^{\text {low }}$ tumours, apparent only in the GBM IDH-wildtype sub-cohort.

The rate of IDH-mutated tumours in our total case collection is comparable with published data $(1,25)$. From the total cohort of consecutive GBM operated/biopsied between 2000-2012 ( $\mathrm{n}=449)$, tissue availability allowed further ana lysis in 237 patients, and $90.3 \%(n=214)$ were IDH-wildtype. Survival data, which were available for 102 patients operated after 2007, after introduction of temozolomide in standard treatment protocols, showed that younger age, IDH1-mutations, MGMT methylation and combined radiation and chemotherapy (temozolomide) were associated with longer survival. This is also in line with previous studies, clearly separating the IDH-wildtype and IDH-mutated subgroups (9,25-27).

EGFR overexpression and amplification strongly correlate in GBM (28), but their prognostic value is still unclear (9,29-33). Reasons for the heterogeneous results may be a lack of patient selection according to e.g. IDH-status or treatment. The degree of EGFR-amplification may also play a role, as depicted in a large cohort of 532 GBM (unknown IDH-status). Temozolomide-treated patients with tumours with highly-amplified and non-amplified EGFR had a longer median survival than those with low/moderate-amplified EGFR (34). We concentrated in the present study on IDH-wildtype GBM, as they are known to often harbour alterations in the EGFR gene. Accordingly, we found an overall higher EGFR expression in IDH-wildtype than the IDH-mutant tumours.

The prognostic value of EGFR expression was demonstrated very recently by Delancre et al (35), who extensively characterized 59 GBM using immunohistochemistry and targeted next generation sequencing (Ampliseq Cancer Hotspot Panel, Ion Torrent) for assessment of mutations (50 genes) and copy number variations (25 genes). Apart from a predictive value of PTEN, they found high EGFR expression to be associated with longer survival in the IDH-wildtype cohort (oral presentation, 7th Belgian Week of Pathology, 2016). We revealed only a statistical trend for the correlation of EGFR expression with better outcome. In our significantly larger cohort, low co-expression of EGFR and its chaperone HSP90 selected patients with worse prognosis, and was independently significant in multivariate models, highlighting the EGFR-HSP90 interaction.

The prognostic value of HSP90 expression is not universal, but depends from the individual tumour entity analysed (36). Only very few studies have assessed HSP90 expression in GBM. Siegelin et al reported a higher expression in tumour tissue compared to adjacent brain tissue (21). Hermisson et al found no correlation between HSP90 expression and progression-free survival in a cohort of 24 IDH-unselected GBM patients (37). We corroborated both results.

EGFR and various downstream molecules are client-proteins of HSP90, providing a rationale for co-expression studies. We revealed that low co-expression was associated with worse prognosis in IDH-wildtype GBM. Though unexpected, this result suggests a variable reliance on the signalling pathway by non-mutated EGFR. Notably, the expression of EGFR stratified most pronounced among $\mathrm{HSP} 90^{\text {low }}$ tumours, whereas the EGFR ${ }^{\text {high }}$ phenotype was associated with longer survival. Even though this result was not independent in multivariate analysis, presumably due to the low number of cases, this points towards a co-regulatory role of HSP90 with EGFR.

HSP90 has emerged as a potential target for anticancer treatment (13). In GBM, HSP90 inhibitors have shown anti-tumoural activity in vitro and in xenograft experiments, as recently summarized (15). In the clinical setting, HSP90 inhibitors may have potential as additive compounds enhancing response to radiotherapy or EGFR-targeted approaches $(12,14,15)$.

The results of the present study may serve as a rationale for targeting HSP90 in highly aggressive GBM, IDH-wildtype. However, further studies are needed to elucidate the biological background behind our results.

\section{Acknowledgements}

The authors gratefully acknowledge the Translational Research Unit and the Molecular Pathology Laboratory of the Institute of Pathology for excellent technical support. We thank Nicole Soell, Department of Neurosurgery, for collecting clinical and survival data.

\section{References}

1. Louis DN, Suvà ML, Burger PC, Perry A, Kleihues P, Aldape KD, Brat DJ, Biernat W, Bigner DD, Nakazato Y, et al: Glioblastoma, IDH-wildtype. In: WHO Classification of Tumours of the Central Nervous System. 4th edition. Louis DN, Ohgaki H, Wiestler OD and Cavenee WK (eds). International Agency for the Research on Cancer, Lyon, pp28-45, 2016.

2. Ostrom QT, Gittleman H, Fulop J, Liu M, Blanda R, Kromer C, Wolinsky Y, Kruchko C and Barnholtz-Sloan JS: CBTRUS statistical report: Primary brain and central nervous system tumors diagnosed in the United States in 2008-2012. Neuro Oncol 17 (Suppl 4): iv1-iv62, 2015.

3. Aldape K, Zadeh G, Mansouri S, Reifenberger G and von Deimling A: Glioblastoma: Pathology, molecular mechanisms and markers. Acta Neuropathol 129: 829-848, 2015.

4. Ohgaki $\mathrm{H}$ and Kleihues P: The definition of primary and secondary glioblastoma. Clin Cancer Res 19: 764-772, 2013.

5. Hartmann C, Hentschel B, Wick W, Capper D, Felsberg J, Simon M, Westphal M, Schackert G, Meyermann R, Pietsch T, et al: Patients with $I D H 1$ wild-type anaplastic astrocytomas exhibit worse prognosis than $I D H 1$-mutated glioblastomas, and IDH1 mutation status accounts for the unfavorable prognostic effect of higher age: Implications for classification of gliomas. Acta Neuropathol 120: 707-718, 2010.

6. Capper D, Weissert S, Balss J, Habel A, Meyer J, Jäger D, Ackermann U, Tessmer C, Korshunov A, Zentgraf $\mathrm{H}$, et al: Characterization of $\mathrm{R} 132 \mathrm{H}$ mutation-specific IDH1 antibody binding in brain tumors. Brain Pathol 20: 245-254, 2010.

7. Ke EE and Wu YL: EGFR as a pharmacological target in EGFRmutant non-small-cell lung cancer: Where do we stand now? Trends Pharmacol Sci 37: 887-903, 2016.

8. Wells A: EGF receptor. Int J Biochem Cell Biol 31: 637-643, 1999. 
9. Ohgaki H, Dessen P, Jourde B, Horstmann S, Nishikawa T, Di Patre PL, Burkhard C, Schüler D, Probst-Hensch NM, Maiorka PC, et al: Genetic pathways to glioblastoma: A population-based study. Cancer Res 64: 6892-6899, 2004.

10. Roskoski R Jr: ErbB/HER protein-tyrosine kinases: Structures and small molecule inhibitors. Pharmacol Res 87: 42-59, 2014.

11. Padfield E, Ellis HP and Kurian KM: Current therapeutic advances targeting EGFR and EGFRvIII in glioblastoma. Front Oncol 5: 5, 2015

12. Whitesell L and Lindquist SL: HSP90 and the chaperoning of cancer. Nat Rev Cancer 5: 761-772, 2005.

13. Calderwood SK and Gong J: Heat shock proteins promote cancer: It's a protection racket. Trends Biochem Sci 41: 311-323, 2016.

14. Combs SE, Schmid TE, Vaupel P and Multhoff G: Stress response leading to resistance in glioblastoma-the need for innovative radiotherapy (iRT) concepts. Cancers 8: 8, 2016.

15. van Ommeren R, Staudt MD, Xu H and Hebb MO: Advances in HSP27 and HSP90-targeting strategies for glioblastoma. J Neuro Oncol 127: 209-219, 2016.

16. Sartori E: Zusammenstellung eines Patienten- und Gewebekollektivs für die Untersuchung von Heat Shock Proteinen und ErbB Rezeptoren in Glioblastomen. Master Thesis, 1-25, 2015.

17. McShane LM, Altman DG, Sauerbrei W, Taube SE, Gion M and Clark GM; Statistics Subcommittee of the NCI-EORTC Working Group on Cancer Diagnostics: Reporting recommendations for tumor marker prognostic studies. J Clin Oncol 23: 9067-9072, 2005.

18. Altman DG, McShane LM, Sauerbrei W and Taube SE: Reporting Recommendations for Tumor Marker Prognostic Studies (REMARK): Explanation and elaboration. PLoS Med 9: e1001216, 2012.

19. Zlobec I, Koelzer VH, Dawson H, Perren A and Lugli A: Next-generation tissue microarray (ngTMA) increases the quality of biomarker studies: An example using CD3, CD8, and $\mathrm{CD} 45 \mathrm{RO}$ in the tumor microenvironment of six different solid tumor types. J Transl Med 11: 104, 2013.

20. Guillaudeau A, Durand K, Pommepuy I, Robert S, Chaunavel A, Lacorre S, DeArmas R, Bourtoumieux S, El Demery M, Moreau JJ, et al: Determination of EGFR status in gliomas: Usefulness of immunohistochemistry and fluorescent in situ hybridization. Appl Immunohistochem Mol Morphol 17: 220-226, 2009

21. Siegelin MD, Habel A and Gaiser T: 17-AAG sensitized malignant glioma cells to death-receptor mediated apoptosis. Neurobiol Dis 33: 243-249, 2009.

22. Hewer E, Beck J, Murek M, Kappeler A, Vassella E and Vajtai I: Polymorphous oligodendroglioma of Zülch revisited: A genetically heterogeneous group of anaplastic gliomas including tumors of bona fide oligodendroglial differentiation. Neuropathology 34: 323-332, 2014.

23. Leu S, von Felten S, Frank S, Vassella E, Vajtai I, Taylor E Schulz M, Hutter G, Hench J, Schucht P, et al: IDH/MGMTdriven molecular classification of low-grade glioma is a strong predictor for long-term survival. Neuro Oncol 15: 469-479, 2013

24. Vassella E, Vajtai I, Bandi N, Arnold M, Kocher V and Mariani L: Primer extension based quantitative polymerase chain reaction reveals consistent differences in the methylation status of the MGMT promoter in diffusely infiltrating gliomas (WHO grade II-IV) of adults. J Neuro Oncol 104: 293-303, 2011
25. Yan H, Parsons DW, Jin G, McLendon R, Rasheed BA, Yuan W, Kos I, Batinic-Haberle I, Jones S, Riggins GJ, et al: IDH1 and IDH2 mutations in gliomas. N Engl J Med 360: 765-773, 2009.

26. Xiu J, Piccioni D, Juarez T, Pingle SC, Hu J, Rudnick J, Fink K, Spetzler DB, Maney T, Ghazalpour A, et al: Multi-platform molecular profiling of a large cohort of glioblastomas reveals potential therapeutic strategies. Oncotarget 7: 21556-21569, 2016.

27. Filippini G, Falcone C, Boiardi A, Broggi G, Bruzzone MG, Caldiroli D, Farina R, Farinotti M, Fariselli L, Finocchiaro G, et al; Brain Cancer Register of the Fondazione IRCCS (Istituto Ricovero e Cura a Carattere Scientifico) Istituto Neurologico Carlo Besta: Prognostic factors for survival in 676 consecutive patients with newly diagnosed primary glioblastoma. Neuro Oncol 10: 79-87, 2008.

28. Horbinski C, Hobbs J, Cieply K, Dacic S and Hamilton RL: EGFR expression stratifies oligodendroglioma behavior. Am J Pathol 179: 1638-1644, 2011.

29. Smith JS, Tachibana I, Passe SM, Huntley BK, Borell TJ, Iturria N, O'Fallon JR, Schaefer PL, Scheithauer BW, James CD, et al: PTEN mutation, EGFR amplification, and outcome in patients with anaplastic astrocytoma and glioblastoma multiforme. J Natl Cancer Inst 93: 1246-1256, 2001.

30. Shinojima N, Tada K, Shiraishi S, Kamiryo T, Kochi M, Nakamura H, Makino K, Saya H, Hirano H, Kuratsu J, et al: Prognostic value of epidermal growth factor receptor in patients with glioblastoma multiforme. Cancer Res 63: 6962-6970, 2003.

31. Simmons ML, Lamborn KR, Takahashi M, Chen P, Israel MA, Berger MS, Godfrey T, Nigro J, Prados M, Chang S, et al: Analysis of complex relationships between age, p53, epidermal growth factor receptor, and survival in glioblastoma patients. Cancer Res 61: 1122-1128, 2001.

32. Batchelor TT, Betensky RA, Esposito JM, Pham LD, Dorfman MV, Piscatelli N, Jhung S, Rhee D and Louis DN: Age-dependent prognostic effects of genetic alterations in glioblastoma. Clin Cancer Res 10: 228-233, 2004.

33. Tini P, Pastina P, Nardone V, Sebaste L, Toscano M, Miracco C, Cerase A and Pirtoli L: The combined EGFR protein expression analysis refines the prognostic value of the MGMT promoter methylation status in glioblastoma. Clin Neurol Neurosurg 149: $15-21,2016$

34. Hobbs J, Nikiforova MN, Fardo DW, Bortoluzzi S, Cieply K, Hamilton RL and Horbinski C: Paradoxical relationship between the degree of EGFR amplification and outcome in glioblastomas. Am J Surg Pathol 36: 1186-1193, 2012.

35. Delancre C, Le Mercier M and Trepant A: P04-Use of immunohistochemistry and next generation sequencing for the classification of glioblastomas. 7th Belgian Week of Pathology, 2016.

36. Ciocca DR and Calderwood SK: Heat shock proteins in cancer: Diagnostic, prognostic, predictive, and treatment implications. Cell Stress Chaperones 10: 86-103, 2005.

37. Hermisson M, Strik H, Rieger J, Dichgans J, Meyermann R and Weller M: Expression and functional activity of heat shock proteins in human glioblastoma multiforme. Neurology 54: $1357-1365,2000$ 